\title{
Efficient deep-red light-emitting electrochemical cells based on a perylenediimide-iridium-complex dyad $\dagger$
}

\author{
Rubén D. Costa, ${ }^{a}$ Francisco J. Céspedes-Guirao, ${ }^{b}$ Enrique Ortí ${ }^{a}$ Henk J. Bolink, ${ }^{* a}$ \\ Johannes Gierschner, ${ }^{a c}$ Fernando Fernández-Lázaro ${ }^{* b}$ and Angela Sastre-Santos ${ }^{* b}$
}

Received (in Cambridge, UK) 19th March 2009, Accepted 28th April 2009

First published as an Advance Article on the web 20th May 2009

DOI: $10.1039 / \mathrm{b} 905367 \mathrm{k}$

\begin{abstract}
A two-layer light-emitting electrochemical cell device based on a new perylenediimide-iridium-complex dyad is presented emitting in the deep-red region with high external quantum efficiencies $(3.27 \%)$.
\end{abstract}

Light-emitting electrochemical cells (LECs) based on ionic transition-metal complexes are among the simplest types of organic light-emitting devices (OLEDs). Their configuration mainly consists of an amorphous film of the active compound placed in between two electrodes. ${ }^{1}$ In spite of the disadvantages of LECs compared to OLEDs, like long turn-on time, shorter lifetimes, and lower efficiencies, LECs offer the advantage of using a less-reactive cathode material (aluminium instead of calcium or magnesium) and hence do not require stringent protection from environmental oxygen and water.

Currently, the most widely used compounds in singlecomponent LEC devices are based on homoleptic complexes of $\mathrm{Ru}(\mathrm{II})$ and biscyclometalated heteroleptic complexes of $\operatorname{Ir}($ III) whose positive charge is balanced by large negative counterions such as hexafluorophosphate. ${ }^{1}$ Their use in LECs is mainly due to their high phosphorescence emission quantum yields, short excited triplet state lifetimes and photochemical stability. ${ }^{2,3}$ However, complexes which give rise to efficient devices are not available for the deep-red region. This can be fulfilled by perylenediimides (PDIs), which present an exceptional photochemical stability, are strong light absorbers in the visible and show high fluorescence quantum yields, ${ }^{4-6}$ which makes them interesting candidates for OLEDs. However, PDIs are poor hole conductors, which makes them unsuitable for single-component type devices. LECs additionally rely on the presence of mobile ions, and hence the emitting species must be compatible on the nanoscale with charged species. Single-layer LECs using PDI as n-type emissive material and lithium triflate have been recently reported showing red emission at high applied bias $(+8 \mathrm{~V}){ }^{7}$ A polyimide LEC incorporating perylene and tri(ethylene

${ }^{a}$ Instituto de Ciencia Molecular, Universidad de Valencia, PO Box

22085, Valencia, Spain.E-mail: henk.bolink@uv.es

${ }^{b}$ División de Química Orgánica, Instituto de Bioingeniería, Universidad Miguel Hernández, Elche 03202 (Alicante), Spain. E-mail:fdofdez@umh.es, asastre@umh.es

${ }^{c}$ Madrid Institute for Advanced Studies IMDEA in Nanoscience,

UAM, Modulo C-IX, Av. Tomás y Valiente 7, Campus de

Cantoblanco, 28049 Madrid, Spain

$\dagger$ Electronic supplementary information (ESI) available: Computational details, experimental procedures and compound characterisation. See DOI: 10.1039/b905367k oxide) moieties has been also studied showing a much more intensified electroluminescence than the respective polyimide LED. $^{8}$

Taking into account the previous considerations, we decided to look for a synergistic collaboration between an ionic iridium(III) complex (that functions as the hole conductor and high phosphorescence emitter) and a PDI red fluorescent emitter (that functions as the electron conductor), in an attempt to achieve a high efficiency in the system. Moreover, the covalent linking of the moieties should increase the thermal stability, while avoiding phase separation processes. With this idea in mind, we have synthesized a new dyad consisting of a PDI derivative linked with an ionic iridium complex. The new dyad $\mathbf{1}$, see Scheme $\mathbf{1}$, is used as the single active component in a double-layer LEC device, showing efficient deep-red electroluminescence.

The synthesis of the [PDI-iridium] $\mathrm{PF}_{6}$ dyad $\mathbf{1}$ is outlined in Scheme 1. Condensation of tetra-tert-octylphenoxy monoanhydride monoimide 2 with 5-amino-1,10-phenanthroline ${ }^{9}$ using zinc acetate as the catalyst afforded the phenanthroline substituted bisimide 3 in a good yield. Finally, reaction of 3 with the organometallated dimer tetrakis-(2-phenylpyridine)bis-( $\mu$-chloro)-diiridium(III $)^{10} \quad\left(\left[\operatorname{Ir}(\mathrm{ppy})_{2} \mathrm{Cl}\right]_{2}\right) \quad$ led to the perylenediimide-iridium(III) dyad $\mathbf{1}$ by a bridge-splitting reaction (see $\mathrm{ESI} \dagger$ ). The PDI bay region of dyad $\mathbf{1}$ is

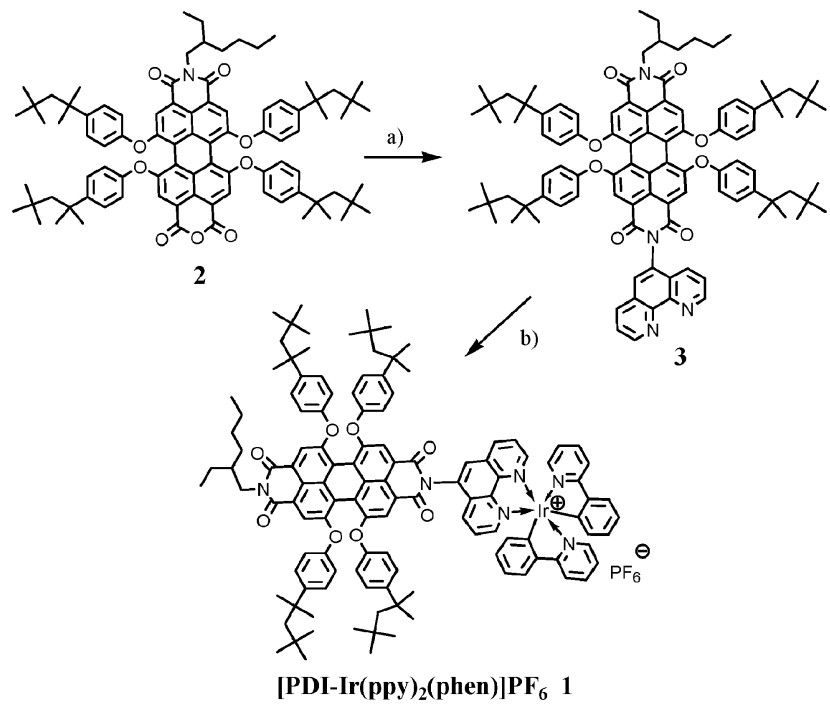

Scheme 1 Synthesis of the [PDI-Ir] $\mathrm{PF}_{6}$ dyad 1. (a) 5-Amino-1,10phenanthroline, $\mathrm{Zn}(\mathrm{AcO})_{2}$, quinoline, $180{ }^{\circ} \mathrm{C}, 10$ hours, $70 \%$ yield; (b) $\left[\operatorname{Ir}(\mathrm{ppy})_{2} \mathrm{Cl}\right]_{2}$, ethylene glycol, reflux, 15 hours, $55 \%$ yield. 

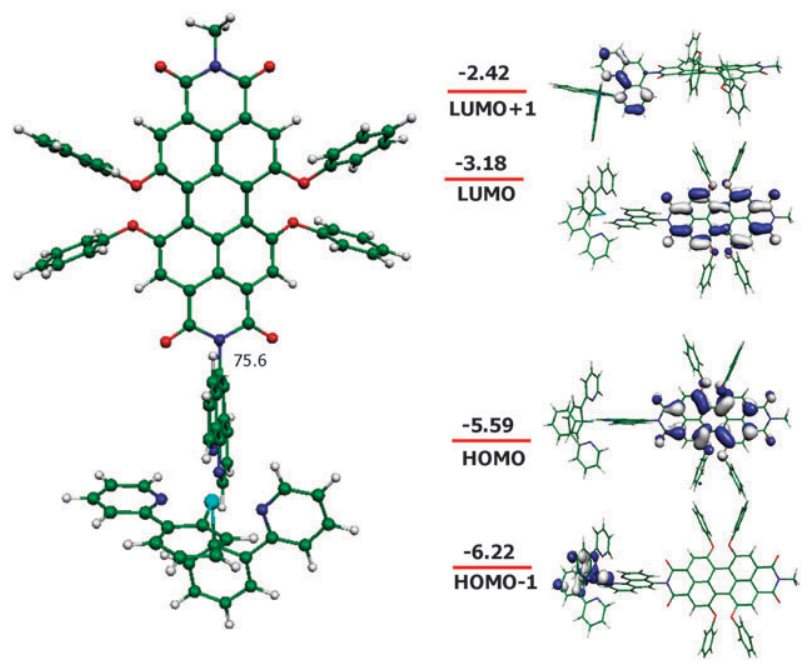

Fig. 1 Left: DFT calculated molecular structure of 1 indicating the dihedral angle between the PDI moiety and the Ir complex. Right: energies $(\mathrm{eV})$ and electronic density contours for the frontier molecular orbitals (in acetonitrile).

substituted with four bulky 4-tert-octylphenoxy groups to disrupt both PDI aggregation and interactions among Ir centers, thus increasing solubility and decreasing PL quenching in the solid state. ${ }^{11-13}$ The solubility of the charged dyad $\mathbf{1}$ is additionally enhanced by a 2-ethylhexyl group at the terminal imide position. ${ }^{14-16}$

As can be observed from density functional theory (DFT) calculations in Fig. 1 (see ESI for details $\dagger$ ), the highest occupied (HOMO) and lowest unoccupied molecular orbitals (LUMO) are located on the PDI moiety, and the HOMOLUMO energy gap $(2.41 \mathrm{eV})$ is therefore dictated by the PDI unit. In contrast, the HOMO- 1 and LUMO +1 orbitals are located on the Ir complex, and their topologies are identical to those found for the HOMO and the LUMO of the free complex. ${ }^{2}$ No overlap between the Ir-complex and the PDI unit is therefore found, and both fragments are electronically decoupled. This is due to the imide group, which interrupts the conjugation, and to the dihedral angle between the phenanthroline and the PDI units in the dyad (calculated to be $76^{\circ}$ ), which hampers the communication between the $\pi$-electron clouds of both moieties (see Fig. 1). The topology of the frontier orbitals suggests that emission should originate from the PDI fragment. Indeed, the photoluminescence (PL) spectrum of 1 (see Fig. 2) exhibits a (somewhat structured) band at $619 \mathrm{~nm}$, similar to the fluorescence spectra of previously reported PDI compounds, ${ }^{17}$ and different to the conventional phosphorescence spectra of Ir-complexes. The high PL quantum yield ( $55 \%$, by irradiation of the PDI unit) and the low lifetime (3.0 ns) recorded for the fluorescence of $\mathbf{1}$ are suitable to expect high-efficient electroluminescence (EL) devices. A quite different behaviour is observed in other PDI-metal complex dyads ${ }^{18-20}$ and triads, ${ }^{21}$ for which PL is quenched by energy transfer to the other moiety.

To verify the performance of the dyad in LECs, we prepared a simple two-layer structure by spin-coating. Prior to the deposition of the active layer, a PEDOT:PSS layer (100 nm) was deposited onto an extensively-cleaned ITO-covered glass

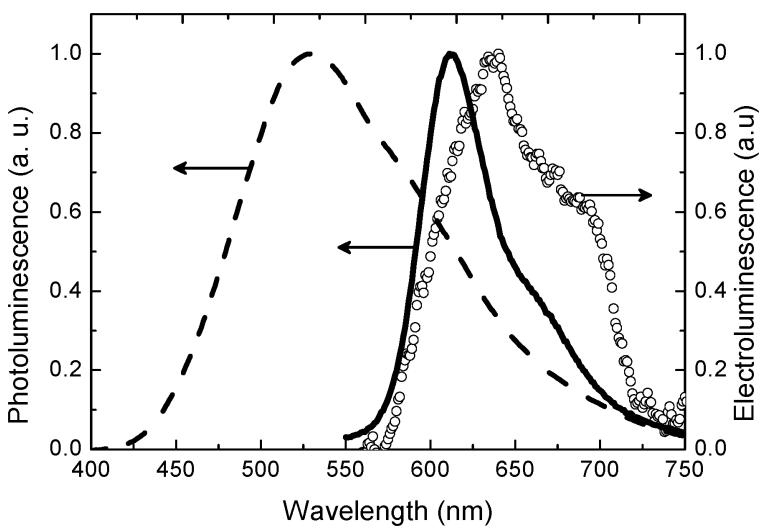

Fig. 2 Photoluminescence spectra of the $\left[\operatorname{Ir}(\mathrm{ppy})_{2}(\mathrm{phen})\right] \mathrm{PF}_{6}$ complex (dashed line) and the PDI-iridium dyad 1 (solid line) in acetonitrile solution. Electroluminescence spectrum of the ITO/PEDOT:PSS/1:IL/Al device (open circles) at an applied bias of $3 \mathrm{~V}$.

substrate. Subsequently, an $80 \mathrm{~nm}$ layer of the active compound 1 was deposited by spin-coating, and an $80 \mathrm{~nm}$ aluminium layer was evaporated as a top contact. To decrease the turn-on time and driving voltage, small amounts of the ionic liquid (IL) 1-butyl-3-methylimidazolium hexafluorophosphate were added to the dyad at a molar ratio of $2: 1$ for $1:$ IL. $^{22}$

The EL spectrum at $3 \mathrm{~V}$ is similar to the PL solution spectrum (see Fig. 2). The red-shift of $25 \mathrm{~nm}$ is ascribed to a solid state effect similar to that observed for Ir complexes. ${ }^{1}$ The CIE coordinates of the emitted light are $x=0.654$ and $y=0.344$ and correspond to a deep-red colour.

Upon applying a bias of $3 \mathrm{~V}$ to the device, current density and luminance slowly increase with time, as typical for LECs, see Fig. 3. The luminance reaches values slightly higher than those reported for LECs based on ionic metal complexes that emit in the same wavelength region. ${ }^{23}$ In fact, high values of current efficiency $\left(2.5 \mathrm{~cd} \mathrm{~A}^{-1}\right)$, maximum power efficiency $\left(2.56 \mathrm{~lm} \mathrm{~W}^{-1}\right)$ and external quantum efficiency $(3.27 \%)$ are reached after approximately 22 minutes of device operation. These values are the highest reported for LEC devices based on charged iridium complexes emitting in the deep-red or near-infrared regions. ${ }^{23} \mathrm{We}$ attribute this improvement to

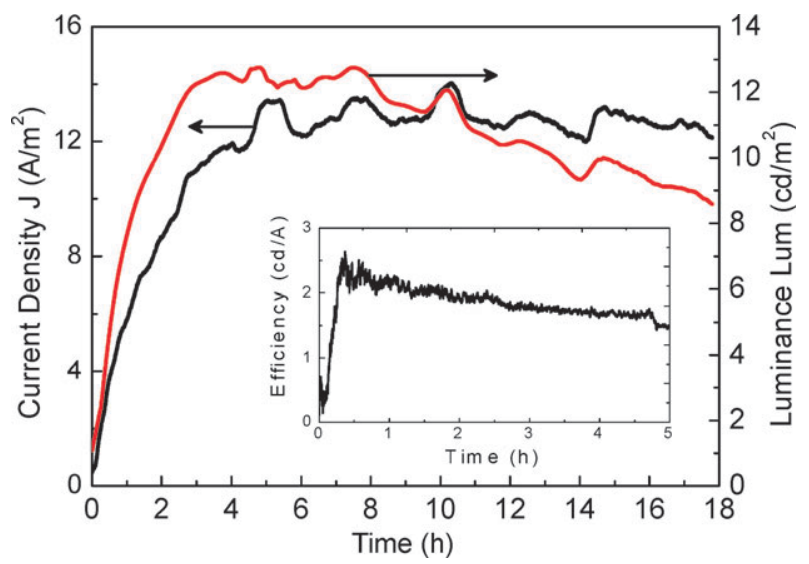

Fig. 3 Current density and luminance $v s$. time at an applied voltage of $3 \mathrm{~V}$ for an ITO/PEDOT:PSS/1:IL/Al device. Inset: efficiency $v$ s. time at $3 \mathrm{~V}$. 
the combination of two effects: (i) the high PL quantum yield (0.55), which increases the radiative recombination, and (ii) the low lifetime of the generated exciton ( $3 \mathrm{~ns}$ ), which decreases its diffusion time. Thus, non-radiative decay processes via impurities or grain defects from the different domains ${ }^{24}$ have less chances to occur.

In conclusion, we have synthesized and characterized a novel charged PDI-iridium complex dyad for LEC applications. The device showed high external EL efficiency in the deep-red region. In-depth photophysical studies of the dyad are on the way.

This work has been supported by the European Union (Heteromolmat, STRP 516982), ESF Eurocores-05SONSFP-021, the Generalitat Valenciana and European FEDER funds, and the Spanish Ministry of Science and Innovation (MICINN; grants MAT2006-28185-E, MAT2007-61584, CTQ2006-14987-C02-02, CTQ2007-67888/BQU, CTQ200805901/BQU，CONSOLIDER-INGENIO CSD2007-00007 and CSD2007-00010). J.G. is a visiting researcher at the ICMol in the framework of the latter program. H.J.B. and J.G. acknowledge the support of the "Ramon y Cajal" program and R.D.C. and F.J.C.G. the support of a FPU grant of the MICINN.

\section{Notes and references}

1 J. D. Slinker, J. Rivnay, J. S. Moskowitz, J. B. Parker, S. Bernhard, H. D. Abruña and G. G. Malliaras, J. Mater. Chem., 2007, 17, 2976-2989.

2 A. B. Tamayo, S. Garon, T. Sajoto, P. I. Djurovich, I. M. Tsyba, R. Bau and M. E. Thompson, Inorg. Chem., 2005, 44, 8723-8732.

3 M. S. Lowry, W. R. Hudson, R. A. Pascal and S. Bernhard, J. Am. Chem. Soc., 2004, 126, 14129-14135.

4 A. Herrmann and K. Müllen, Chem. Lett., 2006, 35, 978-985.

5 F. Würthner, Chem. Commun., 2004, 1564-1579.
6 H. Langhals, Helv. Chim. Acta, 2005, 88, 1309-1343.

7 Z. B. Hill, D. B. Rodovsky, J. M. Leger and G. P. Bartholomew, Chem. Commun., 2008, 6594-6596.

8 H. C. Ko, D. K. Lim, S.-h. Kim, W. Choi and H. Lee, Synth. Met., 2004, 144, 177-181.

9 D. García-Fresnadillo and G. Orellana, Helv. Chim. Acta, 2001, 84, 2708-2730.

10 S. Sprouse, K. A. King, P. J. Spellane and R. J. Watts, J. Am. Chem. Soc., 1984, 106, 6647-6653.

11 C.-C. You and F. Würthner, Org. Lett., 2004, 6, 2401-2404.

12 C. Former, S. Becker, A. C. Grimsdale and K. Müllen, Macromolecules, 2002, 35, 1576-1582.

13 M. Planells, F. J. Céspedes-Guirao, A. Forneli, A. Sastre-Santos, F. Fernández-Lázaro and E. Palomares, J. Mater. Chem., 2008, 18, $5802-5808$.

14 T. Van der Boom, R. T. Hayes, Y. Zhao, P. J. Bushard, E. A. Weiss and M. R. Wasielewski, J. Am. Chem. Soc., 2002, 124, 9582-9590.

15 F. Würthner, C. Thalacker, A. Sautter, W. Schärtl, W. Ibach and O. Hollricher, Chem.-Eur. J., 2000, 6, 3871-3886.

16 S. Chen, Y. Liu, W. Qiu, X. Sun, Y. Ma and D. Zhu, Chem. Mater., 2005, 17, 2208-2215.

17 R. Gvishi, R. Reisfeld and Z. Burshtein, Chem. Phys. Lett., 1993, 213, 338-344.

18 S. Fukuzumi, K. Ohkubo, J. Ortiz, A. M. Gutiérrez, F. FernándezLázaro and A. Sastre-Santos, Chem. Commun., 2005, 3814-3816.

19 A. A. Rachford, S. Goeb and F. N. Castellano, J. Am. Chem. Soc., 2008, 130, 2766-2767.

20 A. Prodi, C. Chiorboli, F. Scandola, E. Iengo, E. Alessio, R. Dobrawa and F. Würthner, J. Am. Chem. Soc., 2005, 127, 1454-1462.

21 S. Fukuzumi, K. Ohkubo, J. Ortiz, A. M. Gutiérrez, F. FernándezLázaro and A. Sastre-Santos, J. Phys. Chem. A, 2008, 112, 10744-10752.

22 S. T. Parker, J. Slinker, M. S. Lowry, M. P. Cox, S. Bernhard and G. G. Malliaras, Chem. Mater., 2005, 17, 3187-3190.

23 H. J. Bolink, L. Cappelli, E. Coronado and P. Gaviña, Inorg. Chem., 2005, 44, 5966-5968.

24 D. R. Blasini, J. Rivnay, D. M. Smilgies, J. D. Slinker, S. FloresTorres, H. D. Abruña and G. G. Malliaras, J. Mater. Chem., 2007, 17, 1458-1461. 